\title{
Recombinant baculovirus vaccine expressing hemagglutinin of H7N9 avian influenza virus confers full protection against lethal highly pathogenic $\mathrm{H} 7 \mathrm{~N} 9$ virus infection in chickens
}

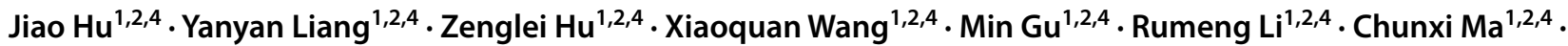 \\ Xiaowen Liu ${ }^{1,2,4}$. Shunlin Hu ${ }^{1,2,4}$. Sujuan Chen ${ }^{1,2,4} \cdot$ Daxin Peng ${ }^{1,2,4} \cdot$ Xinan Jiao ${ }^{2,3,4} \cdot$ Xiufan Liu $^{1,2,4}$
}

Received: 6 July 2018 / Accepted: 11 December 2018 / Published online: 22 January 2019

(c) Springer-Verlag GmbH Austria, part of Springer Nature 2019

\begin{abstract}
The emergent highly pathogenic avian influenza A (H7N9) (HPAI) virus is a major public concern in China. Therefore, it is crucially important to develop an effective vaccine against this virus. In this study, we constructed a baculovirus vaccine expressing the hemagglutinin (HA) of H7N9 strain A/Chicken/Jiaxing/148/2014 (JX148). The recombinant baculovirus (rBac-JX148HA) generated in this study showed good growth in insect cells and good safety, and it stably expressed the HA protein. We compared the immunogenicity and efficacy of the inactivated whole-virus vaccine JX148 and rBac-JX148HA. One chicken in the JX148-treated group died on day 4 post-challenge, and three chickens had typical clinical symptoms (survival rate, 90\%; morbidity, 40\%). However, no chickens immunized with rBac-JX148HA showed clinical signs during the 14-day observation period. An analysis of viral shedding and viral replication demonstrated that rBac-JX148HA more efficiently inhibited viral shedding and viral replication than the inactivated whole-virus vaccine. Taken together, these results indicate that the inactivated recombinant baculovirus vaccine induces a high hemagglutination inhibition antibody titer, provides complete protection against challenge with the highly pathogenic H7N9 virus, and effectively inhibits viral shedding. Therefore, the candidate vaccine has potential utility in the prevention and control of H7N9 avian influenza and is also appropriate for veterinary vaccines using cell suspension culture technology.
\end{abstract}

Handling Editor: Ayato Takada.

Jiao Hu and Yanyan Liang contributed equally to this work.

Electronic supplementary material The online version of this article (https://doi.org/10.1007/s00705-018-04142-4) contains supplementary material, which is available to authorized users.

Xiufan Liu

xfliu@yzu.edu.cn

1 Animal Infectious Disease Laboratory, School of Veterinary Medicine, Yangzhou University, 48 East Wenhui Road, Yangzhou, Jiangsu 225009, China

2 Jiangsu Co-innovation Center for Prevention and Control of Important Animal Infectious Diseases and Zoonosis, Yangzhou University, Yangzhou, Jiangsu, China

3 Jiangsu Key Laboratory of Zoonosis, Yangzhou University, Yangzhou, China

4 Key Laboratory of Prevention and Control of Biological Hazard Factors (Animal Origin) for Agri-food Safety and Quality, Ministry of Agriculture of China (26116120), Yangzhou University, Yangzhou, China

\section{Introduction}

In the spring of 2013, a new triple-reassortant avian influenza virus (AIV) (H7N9 subtype) emerged in China, causing severe human infections and deaths [1]. Subsequent outbreaks of H7N9 influenza in humans have occurred in the winter and spring of every year since then [2,3], and China has now witnessed six epidemic waves of H7N9. According to the statistics from the World Health Organization, there have been a total of 1567 laboratory-confirmed cases of human H7N9 AIV infection, including 615 deaths, as of December 6, 2018 (http://www.fao.org/ag/againfo/progr ammes/en/empres/H7N9/situation_update.html). H7N9 AIV showed low pathogenicity in birds in the first four epidemic waves. However, in the fifth wave, some low-pathogenic H7N9 viruses acquired a "KRTA" insertion at the hemagglutinin (HA) protein cleavage site, thus mutating to highly pathogenic H7N9 viruses [4]. Since then, the highly pathogenic H7N9 AIV has been disseminated to more than 14 provinces of China and has resulted in several outbreaks 
in poultry in China (http://www.fao.org/ag/againfo/progr ammes/en/empres/H7N9/situation_update.html).

Concurrently, 32 human cases of highly pathogenic H7N9 infection have been reported [3, 5-8] (http://www.fao.org/ ag/againfo/programmes/en/empres/H7N9/situation_updat e.html). Therefore, the newly emergent highly pathogenic H7N9 AIV poses a dual challenge for public health and the poultry industry. Infected poultry are the major source of H7N9 viruses, and poultry-to-human transmission is the primary route of human H7N9 infections $[9,10]$. Therefore, the control of H7N9 viruses in poultry is critical for the prevention of H7N9 influenza. Vaccination is one of the most effective ways to constrain AIV infection. However, conventional egg-derived influenza vaccines are limited by several disadvantages, including the unstable supply of chicken embryos, contamination with exogenous viruses, and large amounts of waste.

The baculovirus-insect cell expression vector system (BEVS) is widely used for the expression and production of high-quality recombinant proteins owing to its unique advantages, including excellent safety, high protein expression, posttranslational modification capability, large gene capacity, and easy scale-up. The BEVS has huge commercial potential for producing different types of vaccines for both humans and animals, including recombinant proteins, virus-like particle (VLP) vaccines, and vector vaccines [11, 12]. Exogenous proteins can be exposed and expressed with BEVS, and the host can produce specific immune responses against these antigens. Until now, as far as we know, eight recombinant proteins expressed with the BEVS have been developed as commercial vaccines (Table S1), three of which are for human use and five are for animal use [13, 14].

In this study, the BEVS was used to develop a novel H7N9 vaccine. The main protective antigen of H7N9 AIV, the HA protein, was expressed in the BEVS, and a recombinant baculovirus was generated. The biological characteristics of the recombinant virus were then examined, including its growth, genetic stability, and HA protein expression. The experimental conditions for the inactivation of the recombinant baculovirus were also optimized. An inactivated recombinant baculovirus vaccine was prepared, and its immunogenicity and efficacy were successfully evaluated in chickens.

\section{Materials and methods}

\section{Ethics statement}

This study was performed in strict accordance with the recommendations in the Guide for the Care and Use of Laboratory Animals of the Ministry of Science and Technology of the People's Republic of China. The protocols for all animal experiments were approved by the Jiangsu Administrative Committee for Laboratory Animals (approval number: SYXK-SU-2007-0005) and complied with the guidelines on laboratory animal welfare and ethics of the Jiangsu Administrative Committee of Laboratory Animals. All experiments involving live viruses and animals were performed in negative-pressure isolators with HEPA filters in biosafety level 3 (BSL3) animal facilities, in accordance with the institutional biosafety manual.

\section{Construction of the recombinant baculovirus}

We selected the JX148 strain as the HA gene donor (HA gene accession number, KY005878). The $H A$ gene was amplified by reverse transcription (RT)-PCR and then cloned into the baculovirus transfer vector $\mathrm{pVL1393.} \mathrm{DNA} \mathrm{sequencing} \mathrm{veri-}$ fied that the recombinant transfer vector (pVL1393-JX148HA) containing the $H A$ gene of H7N9 strain JX148 was successfully constructed. Based on the principle of homologous recombination, Sf9 insect cells were cotransfected with plasmid pVL1393-JX148-HA and the linearized genomic DNA of Autographa californica multiple nucleopolyhedrovirus (AcMNPV), and the recombinant baculovirus rBacJX148HA was successfully rescued. After three consecutive rounds of plaque purification, the recombinant virus was purified and then propagated in Sf9 suspension-cultured cells. For confirmation, the H7N9 HA gene inserted into the recombinant baculovirus genome was amplified by PCR and further sequenced. The recombinant virus rBac-JX148HA was serially passaged 15 times in Sf9 cells, and the presence of the $H A$ gene was detected in the viral genome after each passage. After passages 10 and 15, the expression of the HA protein was detected using an indirect immunofluorescence assay (IFA) and western blotting.

\section{Viruses and cell lines}

Strain A/Chicken/Jiaxing/148/2014 (JX148) was isolated from an apparently healthy chicken from a live-poultry market in China during a routine epidemiological investigation of AIV. The highly pathogenic challenge virus A/Chicken/ Duangdong/GD15/2017 (GD15) was isolated from a dead chicken in Guangdong Province of China in 2017.

For the passage or expanded culture of the recombinant rBac-JX148HA virus, Sf9 cells were maintained as suspension cultures in HyQ-SFX insect-serum-free medium (HyClone, Logan, UT) at $27 \pm 2{ }^{\circ} \mathrm{C}$. Recombinant baculovirus stocks were prepared by infecting the cells at a low multiplicity of infection (MOI) of $\leq 0.01$ median tissue culture doses $\left(\mathrm{TCID}_{50}\right)$ per cell. The cells were harvested at 68-72 $\mathrm{h}$ postinfection. 


\section{Indirect immunofluorescence assay}

To determine the expression of the HA protein, Sf9 cells were grown in 24-well plates and infected with the recombinant virus at an MOI of 1 . At 4 days postinfection, the cells were fixed with phosphate-buffered saline (PBS) containing $4 \%$ paraformaldehyde for $20 \mathrm{~min}$, saturated with PBS containing $0.5 \%$ Triton X-100 for $10 \mathrm{~min}$, and then blocked with $10 \%$ bovine serum albumin in PBS for $30 \mathrm{~min}$. The cells were incubated at $37^{\circ} \mathrm{C}$ for $1 \mathrm{~h}$ with a mouse monoclonal antibody $(\mathrm{mAb})$ directed against the HA protein of a human-origin H7N9 virus (A/Anhui/1/2013) (Sino Biological, Beijing, China). The cells were then washed three times with PBS and incubated at $37{ }^{\circ} \mathrm{C}$ for $1 \mathrm{~h}$ with Alexa-Fluor594-conjugated goat anti-mouse $\mathrm{IgG}(\mathrm{H}+\mathrm{L})$ secondary antibody (Sino Biological). After incubation with the secondary antibody, the cells were washed three times with PBS and incubated with 4',6-diamidino-2-phenylindole (DAPI) for $10 \mathrm{~min}$. The cells were examined using a Leica fluorescence microscope.

\section{Western blotting assay}

To further investigate the expression of the HA protein, Sf9 cells were grown in six-well plates and infected with the recombinant virus at an MOI of 1 . At 4 days postinfection, the cells were washed twice with PBS and fractionated to prepare a whole-cell extract using the protocol recommended by the manufacturer (Beyotime Institute of Biotechnology, Nantong, China). The proteins were then subjected to $12 \%$ sodium dodecyl sulfate polyacrylamide gel electrophoresis (SDS-PAGE) and transferred electrophoretically onto polyvinylidene difluoride (PVDF) membranes (Roche Diagnostics Corporation, Indianapolis, IN) using an electrophoresis system (Bio-Rad, Hercules, CA). The membranes were blocked for $1 \mathrm{~h}$ at room temperature with Tris-buffered saline containing Tween 20 (TBST, $20 \mathrm{mM}$ Tris- $\mathrm{HCl}$ [pH 7.4], $137 \mathrm{mM} \mathrm{NaCl}$, and $0.1 \%$ Tween 20 ) containing $5 \%$ skim milk and then incubated overnight at $4{ }^{\circ} \mathrm{C}$ with a primary mAb directed against the HA protein of the H7N9 virus (Sino Biological). The blots were washed three times for 10 min each in TBST buffer and incubated for $1 \mathrm{~h}$ at room temperature with horseradish-peroxidase-conjugated anti-mouse IgG secondary antibody (Sigma, St. Louis, MO).

\section{HA inhibition (HI) assay}

The HA inhibition (HI) assay was performed in duplicate in 96-well microtiter plates. First, the collected test sera were mixed with receptor-destroying enzyme (RDE) (Denka Seiken, Tokyo, Japan) in a ratio of $1: 3$ for $18 \mathrm{~h}$ at $37^{\circ} \mathrm{C}$, heat inactivated for 45 minutes at $56{ }^{\circ} \mathrm{C}$, and allowed to adsorb to chicken erythrocytes in suspension for $60 \mathrm{~min}$ at $4{ }^{\circ} \mathrm{C}$.
The treated sera were serially diluted twofold from 1:10 to $1: 1280$. In each well, a $25-\mu \mathrm{L}$ volume of the diluted serum was incubated with a $25-\mu \mathrm{L}$ volume containing $4 \mathrm{HA}$ units (HAU) of the test virus for $30 \mathrm{~min}$ at $25^{\circ} \mathrm{C}$, to which was then added a $50-\mu \mathrm{L}$ volume of $0.5 \%$ chicken erythrocyte suspension. Virus back-titration was performed in parallel. The reaction plate was incubated for $30 \mathrm{~min}$ at $4{ }^{\circ} \mathrm{C}$, and the end results were read. The final antibody titer was determined as the reciprocal of the highest serum dilution that completely inhibited the hemagglutination reaction.

\section{Optimizing the HA expression conditions for the recombinant virus}

To determine the optimal HA expression conditions for the recombinant virus, Sf9 cells were inoculated with the virus at an MOI of $0.1,0.3$, or 0.5 . On days $2,3,4$, and 5 postinfection, the HA titer in the supernatant or the cell suspension was determined.

\section{Preparation of the antigen}

The recombinant baculovirus rBac-JX148HA was inactivated by treatment with binary ethylenimine (BEI) before the preparation of the antigen. The optimized conditions for BEI inactivation were as follows: the working concentration of BEI was $200 \mathrm{mM}$; the ratio of BEI to antigen was 1:20; incubation was with shaking at $100 \mathrm{rpm}$ for $48 \mathrm{~h}$ at $37^{\circ} \mathrm{C}$. The HA activity and $\mathrm{pH}$ values were monitored during the process of inactivation. Inactivation was further confirmed by isolation of the virus in $\mathrm{Sf} 9$ cells. The inactivated recombinant baculovirus rBac-JX148HA was then prepared by emulsifying the inactivated antigen with the mineral oil adjuvant MONTANIDETM ISA 71R VG (Ron Pharm, Shanghai, China).

As for the preparation of the inactivated whole virus vaccine, the JX148 virus was inactivated with $\beta$-propiolactone before the preparation of the antigen. Specifically, the ratio of $\beta$-propiolactone to antigen was 1:3000, and incubation was done with shaking at $100 \mathrm{rpm}$ for $24 \mathrm{~h}$ at $37^{\circ} \mathrm{C}$. The viruses were inactivated by treatment with $\beta$-propiolactone, which resulted in the complete loss of infectivity of the virus, as confirmed by the absence of detectable infectious virus following inoculation of the vaccines into eggs.

To evaluate the toxicity of the $\beta$-propiolactone according to the Veterinary Pharmacopoeia of the People's Republic of China, a group of 102 - to 3-week-old chickens were injected intramuscularly with $2 \mathrm{~mL}$ of the JX148 inactivated vaccine, and the birds were monitored for clinical signs and morbidity.

Lastly, similar with the recombinant baculovirus rBacJX148HA, the inactivated JX148 whole virus vaccine was then prepared by emulsifying the inactivated antigen with 
the mineral oil adjuvant MONTANIDETM ISA 71R VG (Ron Pharm).

\section{Immunization and challenge of chickens}

The highly pathogenic H7N9 strain GD15 was selected as the challenge virus. For the immunization and protection studies, groups of 3-week-old SPF chickens were randomly divided into three groups: 20 chickens were immunized with the inactivated JX148 whole-virus vaccine (JX148 group); 20 chickens were immunized with the inactivated recombinant baculovirus rBac-JX148HA (baculovirus rBac-JX148HA group); and 15 chickens were not immunized (unimmunized control group). The chickens in the JX148 group and the baculovirus rBac-JX148HA group were immunized by intramuscular injection with $0.6 \mathrm{~mL}$ of vaccine (antigen content, 512 HA units). The birds in the control group were inoculated with $0.6 \mathrm{~mL}$ of PBS. At 4 weeks post-inoculation, the chickens were challenged with $10^{6.0}$ median egg-infective doses $\left(\mathrm{EID}_{50}\right)$ of the GD15 virus by the intranasal route.

To detect viral shedding and viral replication, the three groups of challenged birds were each further randomly divided into two small groups (for the vaccine group, each small group contained 10 birds; for the control group, one small group contained 10 birds, and another small group contained 5 birds). Birds from the small test groups were euthanized on days 3, 5, and 7 post-challenge (three birds from each group on each day), and organ tissue samples (lungs, brain and colon) were collected for further virus titrations. Another group of birds was observed for clinical symptom and mortality and also for collecting oropharyngeal and cloacal swabs. Viral shedding and viral replication were measured as EID $_{50}$ values in eggs.

\section{Systemic specific IgY antibody responses}

The H7-specific IgY titers were determined using an ELISA kit (KERNEL, PA, USA) according to the manufacturer's instructions. The ELISA plates were coated with $0.25 \mu \mathrm{g}$ of purified HA protein from A/Anhui/1/2013 (Sino Biological) per $\mathrm{mL}$. Serial dilutions $(100 \mu \mathrm{L})$ of chicken sera were added to the plates, and $100 \mu \mathrm{L}$ of HRP-conjugated goat anti-chicken IgY antibody was then added as the secondary antibody. For visualization, $100 \mu \mathrm{L}$ of 3,3',5,5'-tetramethylbenzidine (TMB) liquid substrate was added to each well, and the reaction was stopped by the addition of $50 \mu \mathrm{L}$ of $3 \mathrm{~N}$ hydrochloric acid. The optical density (OD) was measured at $450 \mathrm{~nm}$. The ELISA endpoint titers were defined as the highest serum dilutions at which the mean OD values of duplicate wells were more than twofold above the mean OD value \pm standard deviation $(\mathrm{SD})$ of the sera from the mock control chickens [14].

\section{Statistical analysis}

Statistical analysis was performed using SPSS Statistics software. An independent-samples $t$-test was used for the data analysis. $P<0.05$ was considered significant.

\section{Results}

\section{Generation and characterization of recombinant baculovirus rBac-JX148HA}

The coding sequence of the JX148 HA gene was subcloned into the baculovirus transfer vector pVL1393 to generate pVL1393-JX148-HA. Sf9 cells were cotransfected with pVL1393-JX148-HA and linearized baculoviral DNA to generate the first-generation recombinant virus rBac-JX148HA-P1. As shown in Fig. 1A, the IFA results showed the successful expression of the HA protein from rBac-JX148HA-P1. The rescued virus was then plaque-purified three times in Sf9 cells and used for the production of the fourth-generation recombinant virus rBac-JX148HA-P4. The rBac-JX148HA-P4 virus was serially passaged in Sf9 cells to generate the $15^{\text {th }}$-generation virus rBac-JX148HAP15. After 15 serial passages, the $H A$ gene was amplified (Fig. 1B) and sequenced, and no mutations were detected in the $H A$ gene in the viral genome after any passage. The expression of the HA protein was also successfully detected after passages 10 and 15 (Fig. 1C). Altogether, these results showed that the recombinant baculovirus rBac-JX148HA displays good genetic stability. Furthermore, as shown in Table 1, from passage 7 to 15 , the virus maintained high titers during the process of viral passage, with the highest titer in passage 8 . Therefore, the passage 7 virus was used as the stock virus.

To determine the optimal inactivation conditions for the recombinant virus, Sf9 cells were inoculated with the passage 7 virus (indicated as P7 in Fig. 2) at MOIs of 0.1, 0.3, and 0.5 . On days $2,3,4$, and 5 postinfection, cell culture was used to determine the HA titer in the cell supernatant or the cell suspension. In addition, the empty baculovirus control vector was used as a mock control. As shown in Fig. 2, no HA activity was detected in the mock control group. Moreover, the HA titers in the cell suspension of the three recombinant-virus-infected groups were higher than in the cell supernatant. However, there was no significant difference in the HA titers in the cell suspensions of the three groups, except that the virus inoculated at an MOI of 0.1 had a lower HA titer at 2 days postinfection. Therefore, for preparation of the recombinant baculovirus vaccine, the passage 7 virus was inoculated at an MOI of 0.3 , and the cell suspension was used for further antigen preparation. 
A
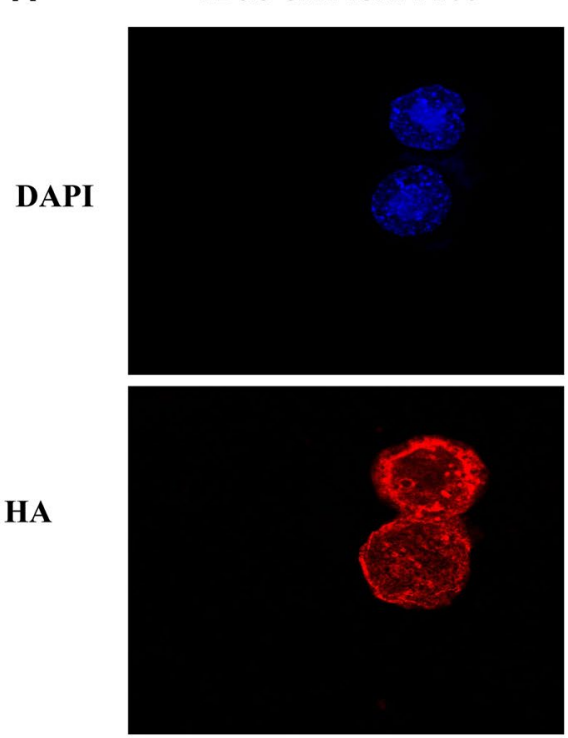

HA

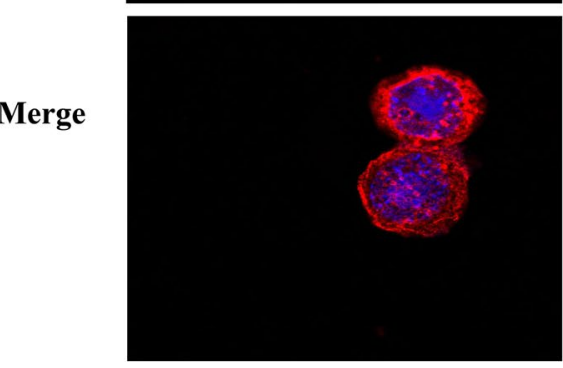

B

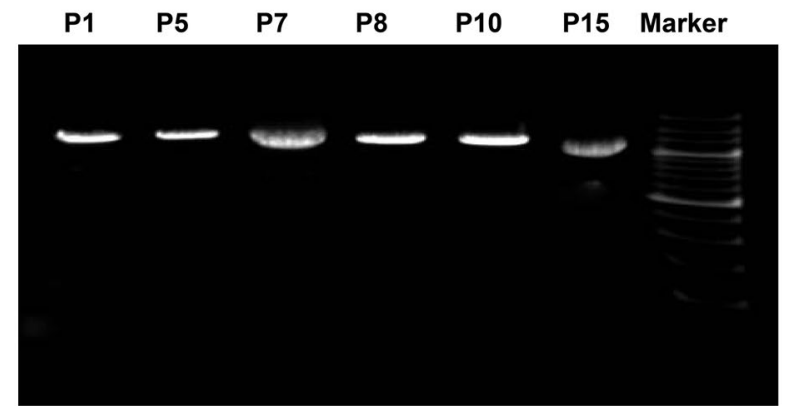

rBac-JX148HA 40x
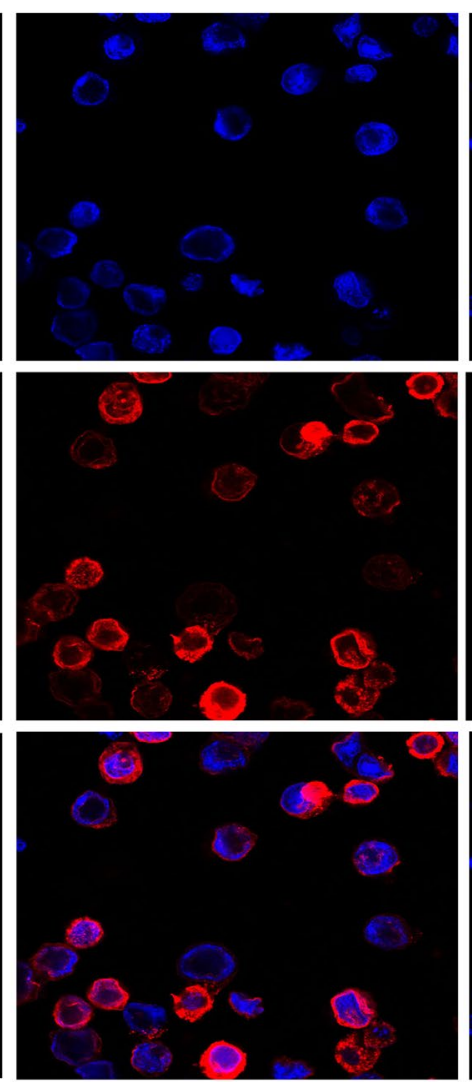

Empty Vector $40 \times$
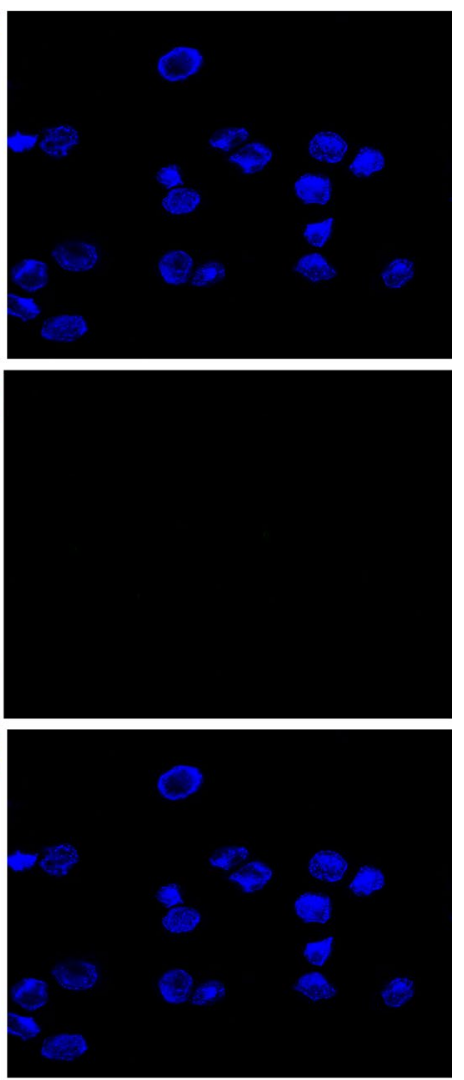

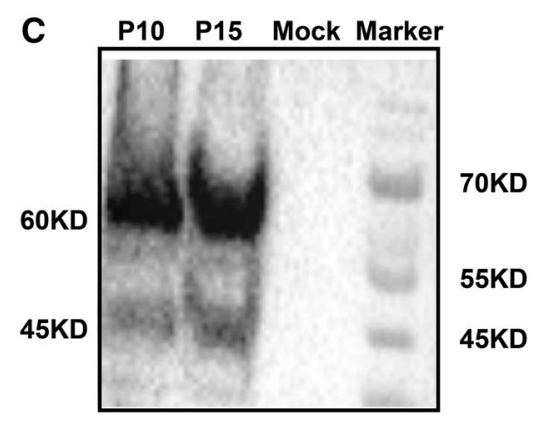

Fig. 1 Generation and characterization of the recombinant baculovirus rBac-JX148HA. (A) The rescued virus rBac-JX148HA was successfully identified using an immunofluorescence assay (IFA). The empty baculovirus was used as a mock control, and no HA specific immune fluorescence was detected in the mock cells. (B) The viruses

\section{Inactivated rBac-JX148HA vaccine induces a higher $\mathrm{HI}$ antibody titer in chickens}

To evaluate the toxicity of the $\beta$-propiolactone, ten 2 -to 3 -week-old chickens were injected intramuscularly with $2 \mathrm{~mL}$ of the JX148 inactivated vaccine, and the birds were monitored for clinical signs and morbidity. The results showed that all of the birds survived during the observation period, and no clinical signs were observed. Moreover, no from passages $1,5,7,8,10$, and 15 were verified by PCR amplification of the HA gene. (C) The passage 10 virus rBac-JX148HA-P10 and the passage 15 virus rBac-JX148HA-P15 were confirmed by detecting the expression of HA by western blotting. Cells infected with an empty baculovirus were used as a mock control

local or systemic adverse response was observed in any of the birds. To evaluate the immunogenicity of the inactivated rBac-JX148HA vaccine, a group of chickens treated with the inactivated whole-virus JX148 vaccine and a PBS-treated mock control group were included for comparison. Two kinds of test antigen were also used, the low-pathogenicity JX148 virus and the highly pathogenic GD15 virus. As shown in Fig. 3A and B, no HI activity was detected from the mock control group. Moreover, when tested with either 
Table 1 Virus titers of the recombinant baculovirus of different passages

\begin{tabular}{ll}
\hline Virus & $\left(\mathrm{TCID}_{50} / \mathrm{mL}\right)$ \\
\hline rBac-JX148HA-p5 & $10^{4.7}$ \\
rBac-JX148HA-p6 & $10^{6.5}$ \\
rBac-JX148HA-p7 & $10^{7.9}$ \\
rBac-JX148HA-p8 & $10^{8.8}$ \\
rBac-JX148HA-p9 & $10^{7.8}$ \\
rBac-JX148HA-p10 & $10^{7.6}$ \\
rBac-JX148HA-p11 & $10^{7.57}$ \\
rBac-JX148HA-p12 & $10^{7.8}$ \\
rBac-JX148HA-p13 & $10^{7.2}$ \\
rBac-JX148HA-p14 & $10^{7.29}$ \\
rBac-JX148HA-p15 & $10^{7.6}$ \\
\hline
\end{tabular}

the JX148 or GD15 antigen, the recombinant baculovirus vaccine induced higher $\mathrm{HI}$ antibody titers than the inactivated whole-virus vaccine at 2,3 , and 4 weeks postimmunization (Fig. 3C and D). Specifically, at 4 weeks postimmunization, when JX148 was used as the test antigen, only $60 \%$ of the birds in the inactivated whole-virus JX148 group reached an HA titer of $\geq 4 \log _{2}$, whereas this was $90 \%$ in the rBac-JX148HA group (Fig. 3C and E). At the same time point, when GD15 was used as the test antigen, only 50\% of the birds in the inactivated whole-virus JX148 group reached an HA titer of $\geq 4 \log _{2}$, whereas the corresponding number for rBac-JX148HA group was 70\% (Fig. 3D and F). Moreover, the mean HI titers against the JX148 and GD15 antigens were both higher in the rBac-JX148HA group than in the inactivated whole-virus JX148 group (Fig. 3C-F). Taken together, these results indicate that the inactivated rBac-JX148HA vaccine induced higher HI antibody titers in chickens than the inactivated whole-virus JX148 vaccine.

\section{Inactivated rBac-JX148HA vaccine provides full protection from lethal challenge with highly pathogenic H7N9 virus}

At 4 weeks postimmunization, chickens were challenged with $10^{6.0} \mathrm{EID}_{50}$ of the highly pathogenic strain GD15 and were observed for clinical signs and mortality for 14 days. In the PBS-treated mock control group, one chicken died 3 days post-challenge, and the other birds all died within 7 days (Fig. 4A). The birds showed typical clinical signs, such as purple comb, hemorrhage of foot scale, palpebral edema, and nervous disorders (twisting the neck). In the JX148 group, one chicken died on day 4 post-challenge, two birds showed purple comb and haemorrhage of foot scale, and one bird showed ocular conjunctivitis, resulting a survival rate of 90\% (Fig. 4A). However, no chickens immunized with the recombinant baculovirus showed any clinical signs during

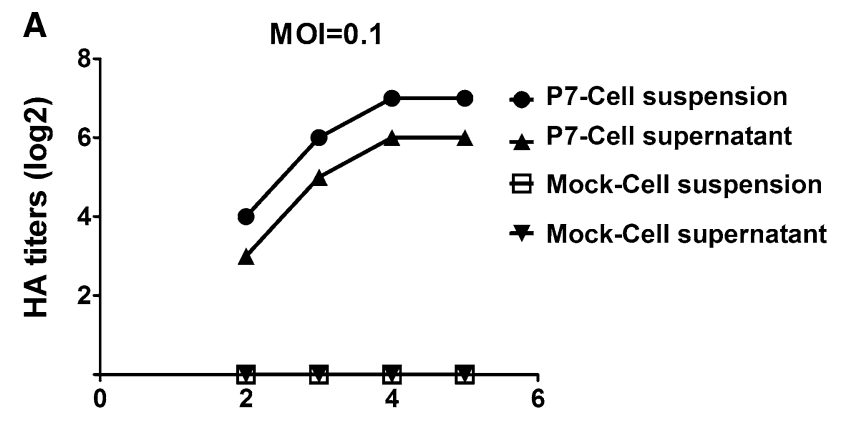

Days post infection
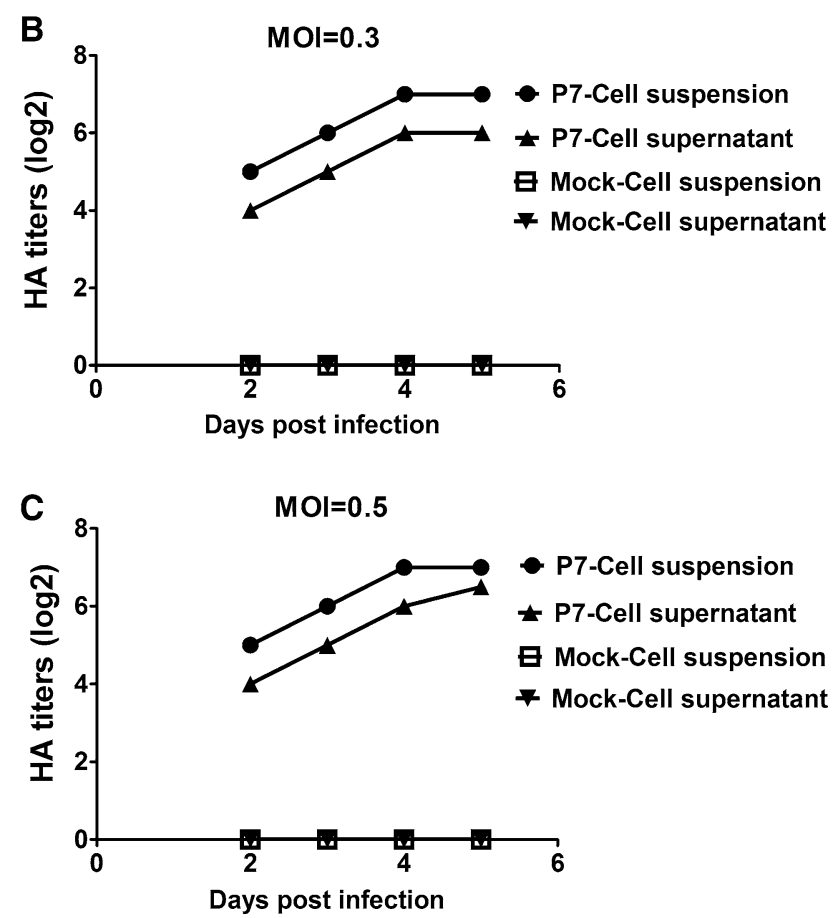

Fig. 2 Optimizing the HA expression conditions for the recombinant virus. Sf9 cells were inoculated with the passage 7 virus at a multiplicity of infection of $0.1,0.3$, or 0.5 . On days $2,3,4$, and 5 postinfection, cell culture was used to determine the HA titer in the cell supernatant or in the cell suspension

the 14-day observation period, and the survival rate was $100 \%$ (Fig. 4A). Taken together, these results indicate that the inactivated recombinant baculovirus vaccine provided complete protection against challenge with a lethal dose of highly pathogenic $\mathrm{H} 7 \mathrm{~N} 9$ virus.

\section{Inactivated rBac-JX148HA vaccine significantly restricts viral shedding and viral replication}

At 4 weeks postimmunization, the chickens were challenged with $10^{6.0} \mathrm{EID}_{50}$ of the highly pathogenic strain GD15, and swabs were collected for virus titration. The results showed that $100 \%$ of the PBS-treated mock control group shed the virus, whereas the proportions of chickens 
Fig. $3 \mathrm{HI}$ antibody titers induced by the H7N9 vaccines in chickens. To evaluate the immunogenicity of the inactivated rBac-JX148HA vaccine, chickens immunized with the inactivated whole-virus JX148 vaccine and an unimmunized mock control group of chickens were included for comparison. In addition, two kinds of antigen were used, the low-pathogenicity JX148 virus (LP virus) and the highly pathogenic GD15 virus (HP virus). (A) HI antibody titers for the negative mock control group, using JX148 virus as the test antigen. (B) HI antibody titers in the negative mock control group, using GD15 virus as the test antigen. (C) $\mathrm{HI}$ antibody titers induced by the inactivated whole-virus JX148 vaccine, using JX148 virus as the test antigen. (D) HI antibody titers stimulated by the inactivated whole-virus JX148 vaccine, using GD15 virus as the test antigen. (E) HI antibody titers induced by the inactivated $\mathrm{rBac}$ JX148HA vaccine, using JX148 virus as the test antigen. (F) The $\mathrm{HI}$ antibody titers stimulated by the inactivated rBac-JX148HA vaccine. GD15 virus was used as the test antigen

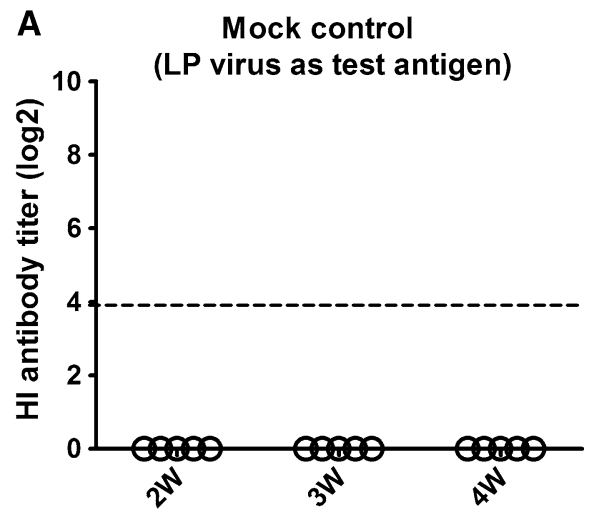

C

JX148

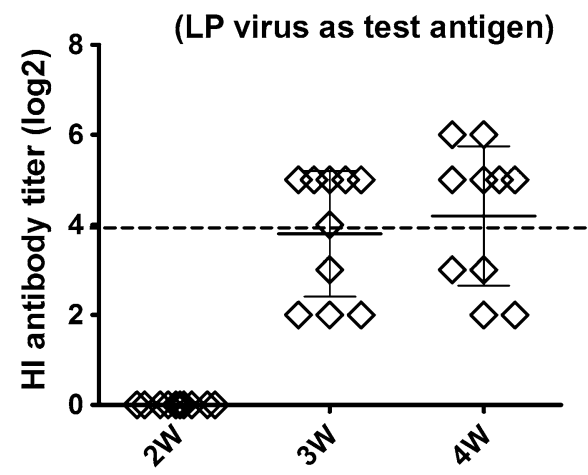

E

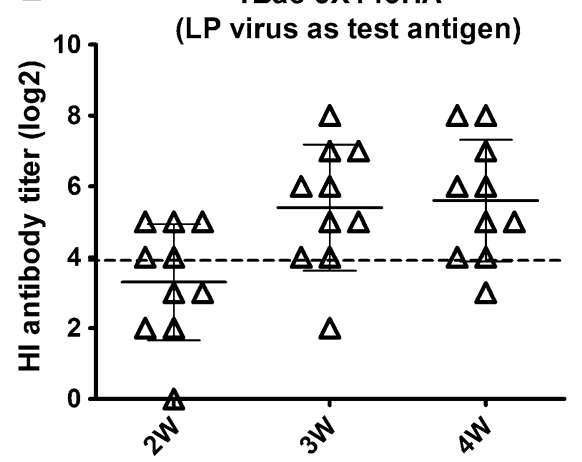

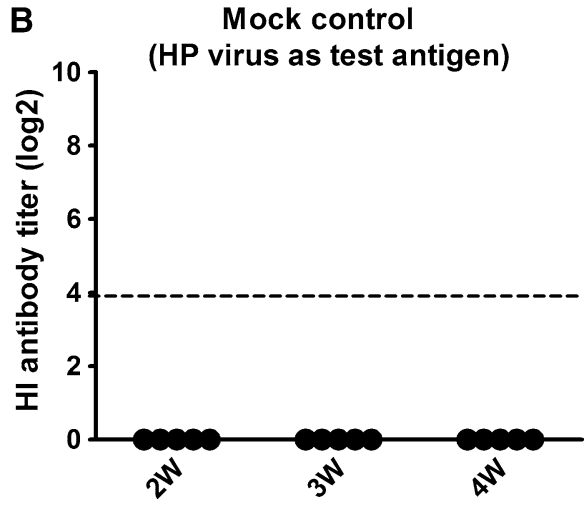

D

JX148

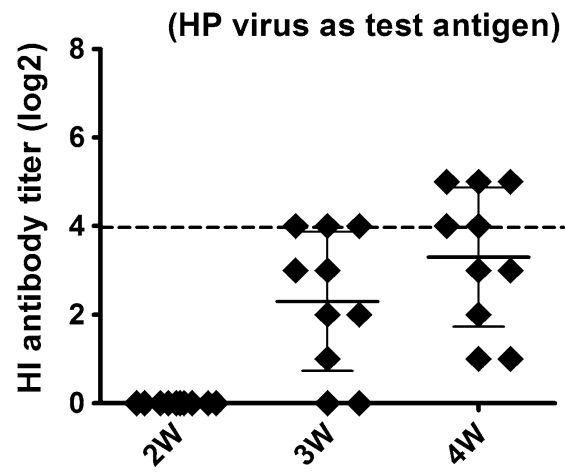

$\mathbf{F}$

rBac-JX148HA (HP virus as test antigen)

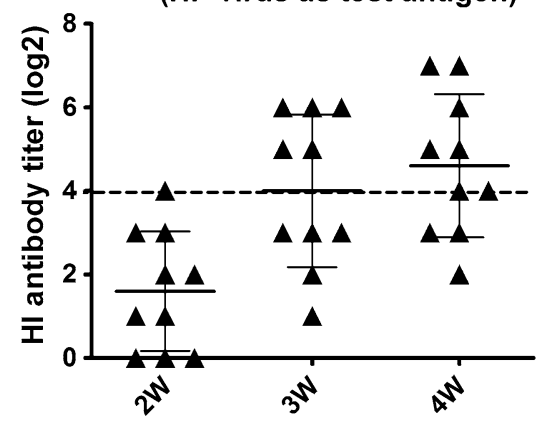

in the JX148 group and rBac-JX148HA group that shed the virus were $70 \%$ and $40 \%$, respectively (Fig. 4B and C). We then determined the viral titers in these positive samples. On days 3 and 5 postchallenge, in both laryngotracheal and cloacal swabs, the viral titers in the PBS group were significantly higher than in the JX148 and rBac-JX148HA groups (Fig. 4B and C). Moreover, during the whole observation period, the viral titer was higher in the JX148 group than in the rBac-JX148HA group in both the laryngotracheal and cloacal swabs (Fig. 4B and C). Notably, on day 3 postchallenge, the viral titers in the laryngotracheal and cloacal swabs were significantly higher in the JX148 group than in the rBac-JX148HA group (Fig. 4B and C). As for viral replication, the viral titers in the lung were significantly higher in the mock group than in the JX148 and rBac-JX148HA groups on day 3 postchallenge (Fig. 4D). Moreover, viral titers in the JX148 group were significantly higher than in the rBacJX148HA group at this time point, and JX148 viruses were recovered from more birds than $\mathrm{rBac}-\mathrm{JX} 148 \mathrm{HA}$ virus on days 5 and 7 postchallenge (Fig. 4D). As for viral replication in the brain and colon, during the whole observation period, JX148 virus was recovered from more birds than rBac-JX148HA virus (Fig. 4E and F). Therefore, these results demonstrate that the recombinant baculovirus vaccine was more efficient in inhibiting viral shedding and viral replication than the inactivated whole-virus vaccine. 
A

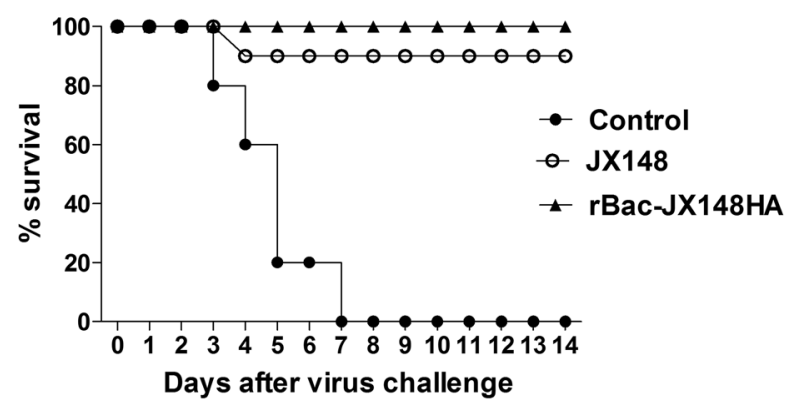

B

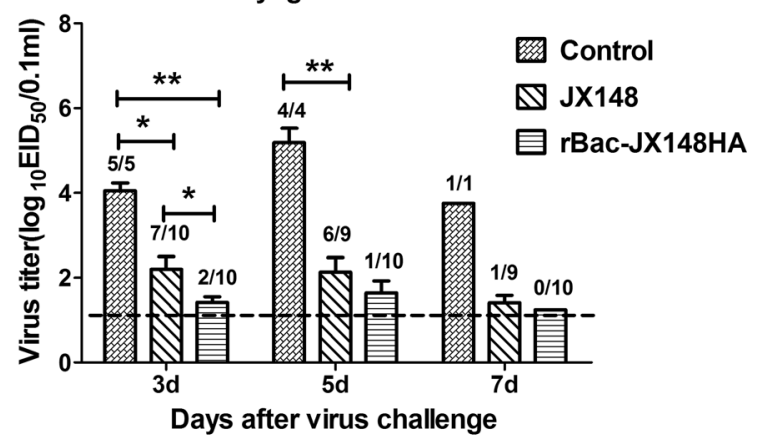

C

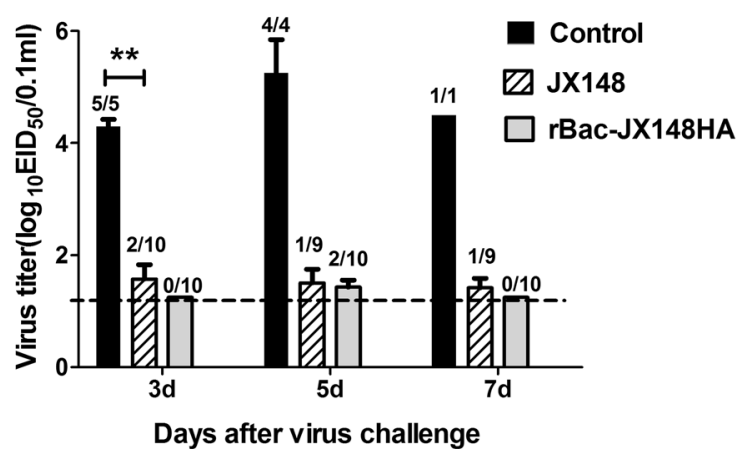

Fig. 4 Quantification of replication and shedding of the challenge virus. On days 3,5 , and 7 postinfection, laryngotracheal and cloacal swabs were collected to quantify viral shedding by measuring the $50 \%$ embryo infectious dose $\left(\mathrm{EID}_{50}\right)$ in eggs. **, $P<0.01$, *, $P<0.05$, significant different between two groups. The number on

\section{Inactivated rBac-JX148HA vaccine induces a stronger $\mathrm{H7}$-specifc IgY antibody response}

The animal challenge study showed that although 50\% of the birds in the JX148 group and 30\% of the birds in the rBac-JX148HA group produced undetectable levels of HI antibodies against the GD15 antigen, 90\% and $100 \%$ of the birds, respectively, survived a lethal challenge with the HPAI H7N9 virus. To investigate the reason for this, we determined the $\mathrm{H} 7$-specific IgY antibody
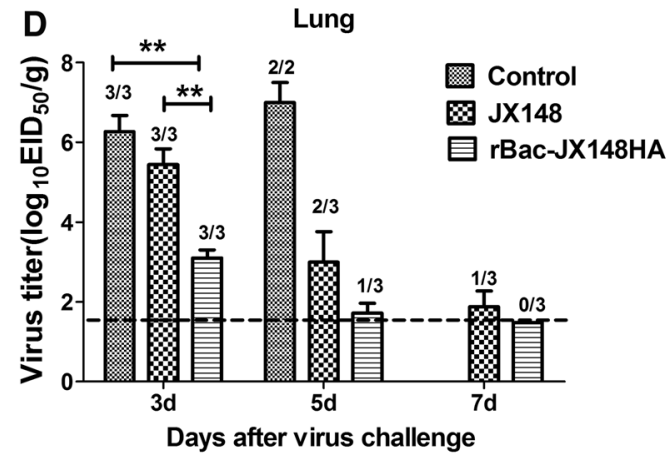

E

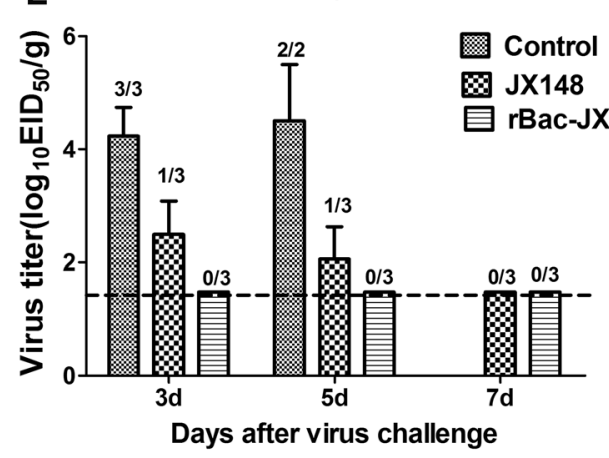

F Colon

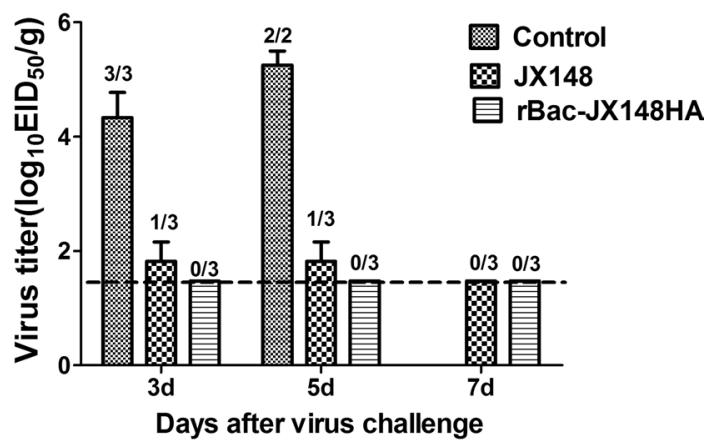

the column indicates the number shedding divided by the total. (A) Survival rate of the birds after intranasal inoculation with the highly pathogenic H7N9 virus. (B) Virus titration in laryngotracheal swabs. (C) Virus titration in cloacal swabs. (D) Virus replication in the lung. (E) Virus replication in the brain. (F) Virus replication in the colon

titers in the samples in which the HI titers were below 4 $\log _{2}$. As shown in Fig. 5, both the rBac-JX148HA and JX148 groups displayed a positive IgY antibody response, as demonstrated using an ELISA. Moreover, the overall IgY antibody titer was significantly higher in the rBacJX148HA group than in the JX148 group (Fig. 5). These results indicate that although the HI titers were negative, the high IgY antibody levels provided clinical protection against the highly pathogenic H7N9 virus. 

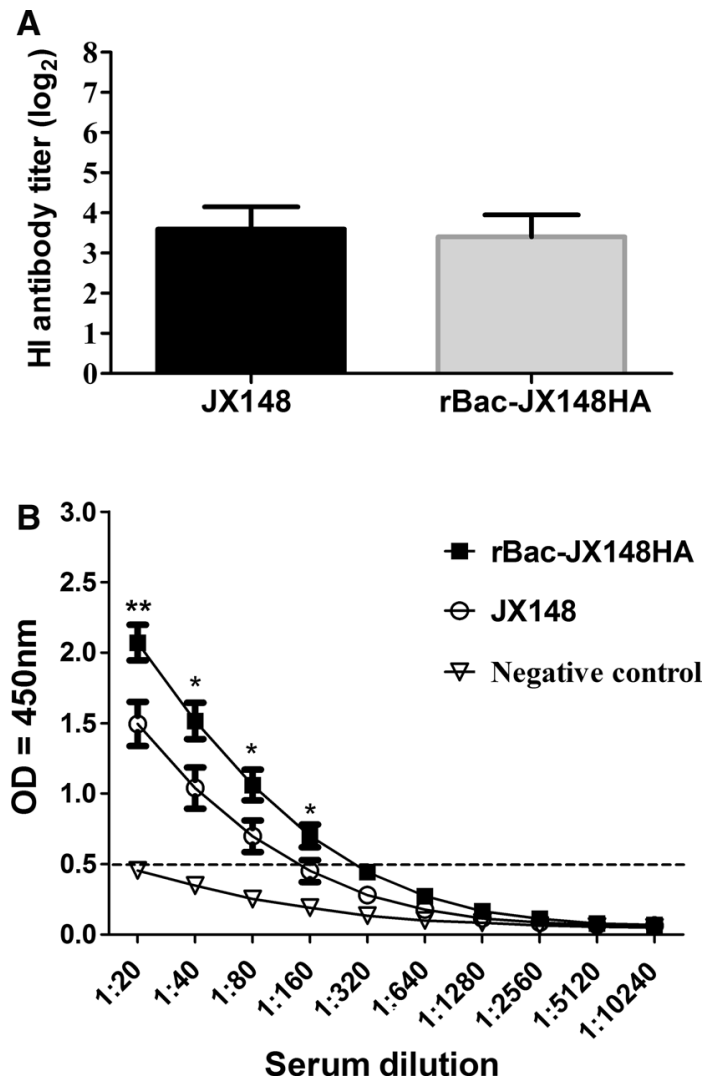

Fig. 5 ELISA antibody test. To determine the reason for the excellent protection afforded by the recombinant rBac-JX148HA virus, we compared the H7-specific IgY antibodies in the samples with $\mathrm{HI}$ titers of $<4 \log _{2}$ in the JX148-treated group and the rBac-JX148HAtreated group. (A) HI antibody titers of selected samples. (B) H7-specific IgY titers determined using an ELISA kit

\section{Discussion}

The first human H7N9 infection was reported in February 2013, in China. Since then, there has been a wave of H7N9 avian influenza every spring and winter [2, 3]. Notably, the fifth wave in the winter of 2016 displayed a sharp increase in human cases, and a highly pathogenic variant also emerged in this period, which poses a great threat to both poultry and human health [2]. Although H7N9 AIVs are not transmitted efficiently among humans, recent studies have shown that they have acquired the capacity for efficient airborne transmission in ferrets after a single round of replication $[15,16]$. Therefore, there is great concern that the H7N9 virus might acquire both lethality and transmissibility with additional mutations or reassortment and cause a pandemic in humans. To effectively control H7N9 avian influenza, it is particularly important to develop a safe and effective vaccine against this subtype virus. In this study, a BEVS expressing the H7N9 subtype AIV HA protein was designed to provide a potentially effective tool to prevent and control epidemic H7N9 avian influenza infections in poultry.

The $\mathrm{HI}$ antibody titer is usually used as an immunological index of the serological protection afforded by avian influenza vaccines, and an $\mathrm{HI}$ antibody titer $\geq 4 \log _{2}$ is considered to have a clinically protective effect [10]. When we used the early 2013 virus JX148 as the test antigen, seroconversion was induced in $90 \%$ of the rBac-JX148HA-treated chickens (Fig. 3E), whereas this was $70 \%$ when the 2017 virus GD15 was used (Fig. 3F). However, the seroconversion rate was lower in the JX148 group than in the rBac-JX148HA group when using JX148 or GD15 as test antigen (Fig. 3C and D). Moreover, rBac-JX148HA induced higher HI titers than JX148. Therefore, the immunogenicity of rBac-JX148HA was superior to that of JX148. It has been reported that the baculovirus has a certain immune adjuvant effect, which can enhance the immune response to vaccines [17]. In this study, the higher immunogenicity of rBac-JX148HA may have been associated with the immune adjuvant effect of the baculovirus.

The results of the challenge study showed that JX148 protected $60 \%$ of the birds against highly pathogenic H7N9 challenge, whereas rBac-JX148HA conferred full protection (Fig. 4A). Moreover, rBac-JX148HA was more effective in inhibiting viral shedding and viral replication than JX148 (Fig. 4B-F). In this study, the early 2013 viral strain JX148 was used as the HA donor. HA is a surface glycoprotein of AIVs with strong immunogenicity and is the main target protein in vaccine development. The HA protein is also the viral protein most frequently mutated under immune stress. It has been reported that there is clear antigenic specificity between the highly pathogenic and low-pathogenic H7N9 viruses. Antiserum against low-pathogenic H7N9 viruses was less reactive to highly pathogenic AIVs, and its titer was at least four times lower than that of homologous HI $[18,19]$ (http://www.who.int/influenza/vaccines/virus/characteristics _virus_vaccines/en/). However, in the present study, even if there were some antigenic differences between the antigen proteins expressed by the recombinant baculovirus and the highly pathogenic AIV strain, the rBac-JX148HA vaccine still provided complete protection (Fig. 4A). Similarly, $\mathrm{Hu}$ et al. reported that a recombinant Newcastle disease virus expressing the HA protein of strain JX148 provided 80\% protection against a highly pathogenic strain (A/chicken/ Guangxi/GX100/2017, GX100) [20]. These results show that although there are antigenic differences between lowpathogenicity and highly pathogenic H7N9 AIVs, some level of cross-protection between the two types of pathogenic $\mathrm{H} 7 \mathrm{~N} 9$ is possible.

The protective effect of the inactivated recombinant baculovirus vaccine is also related to IgY antibodies. Several studies have shown that the HI antibody titers induced by H7N9 vaccines are generally low, whereas the levels 
of $\mathrm{IgG}$ antibodies induced by $\operatorname{IgG}$ vaccines are higher [21-23]. IgG antibodies also play a protective role through their Fc-domain-mediated antibody-dependent cytotoxicity and phagocytosis. Tan et al. found that injecting an anti-H7-HA mAb with no HI activity into mice allowed them to resist infection by an $\mathrm{H} 7 \mathrm{~N} 9$ virus, suggesting that HA-specific IgG antibodies are protective [24]. In the present study, the seroconversion rate for the rBac-JX148HAtreated chickens was $90 \%$, whereas the protective rate was 100\% (Fig. 3E and Fig. 4A). We surmise that the high IgY antibodies in the HI-negative birds may have conferred clinical protection (Fig. 5). Therefore, in addition to traditional HI antibodies, the levels of IgY antibodies should also be used as an indicator of the immunogenicity of H7N9 vaccines.

In summary, an inactivated candidate vaccine, rBacJX148HA, based on a recombinant baculovirus encoding the $\mathrm{H} 7$ antigen, was successfully developed. The recombinant virus showed good growth in insect cells and good safety, and it stably expressed the HA protein. This candidate vaccine induced both high $\mathrm{HI}$ titers against H7N9 antigens and high levels of H7-HA-reactive IgY antibodies. The recombinant vaccine rBac-JX148HA provided $100 \%$ protection against a lethal-dose challenge with a highly pathogenic H7N9 virus. A significant reduction in viral shedding and viral replication was also observed compared with the inactivated whole-virus vaccine and that in unvaccinated controls. Our results also indicate that the HA-specific $\operatorname{IgG}$ antibodies may partially contribute to protection against the highly pathogenic $\mathrm{H} 7 \mathrm{~N} 9$ virus.

Funding This work was supported by the National Key Research and Development Project of China (2016YFD0501601 and 2016YFD0500202-1), the Jiangsu Provincial Natural Science Foundation of China (BK20150444), the National Natural Science Foundation of China (31502076), the Postdoctoral Science Foundation of Jiangsu Province, China (1501015B), a Special Financial Grant from the China Postdoctoral Science Foundation (2016T90515), the "Qing Lan Project" of Higher Education Institutions of Jiangsu Province, China, the "High-end Talent Support Program" of Yangzhou University, China, the Natural Science Foundation of the Higher Education Institutions of Jiangsu Province, China (15KJB230006), the Earmarked Fund For China Agriculture Research System (CARS-40), and the Project Funded by the Priority Academic Program Development of Jiangsu Higher Education Institutions (PAPD).

\section{Compliance with ethical standards}

Conflict of interest The authors declare that this research was conducted in the absence of any commercial or financial relationships that could be construed as a potential conflict of interest.

Ethical approval All applicable international, national, and/or institutional guidelines for the care and use of animals were followed.

Consent for publication All authors consent to publication.

\section{References}

1. Gao RB, Cao B, Hu YW, Feng ZJ, Wang DY, Hu WF, Chen J, Jie ZJ, Qiu HB, Xu K, Xu XW, Lu HZ, Zhu WF, Gao ZC, Xiang NJ, Shen YZ, He ZB, Gu Y, Zhang ZY, Yang Y, Zhao X, Zhou L, Li XD, Zou SM, Zhang Y, Li XY, Yang L, Guo JF, Dong J, Li Q, Dong LB, Zhu Y, Bai T, Wang SW, Hao P, Yang WZ, Zhang YP, Han J, Yu HJ, Li DX, Gao GF, Wu GZ, Wang Y, Yuan ZH, Shu YL (2013) Human infection with a novel avian-origin influenza A (H7N9) virus. New Engl J Med 368(20):1888-1897. https://doi.org/10.1056/Nejmoa1304459

2. Su S, Gu M, Liu D, Cui J, Gao GF, Zhou JY, Liu XF (2017) Epidemiology, evolution, and pathogenesis of H7N9 influenza viruses in five epidemic waves since 2013 in China. Trends Microbiol 25(9):713-728. https://doi.org/10.1016/j. tim.2017.06.008

3. Wang XL, Jiang H, Wu P, Uyeki TM, Feng LZ, Lai SJ, Wang LL, Huo X, Xu K, Chen EF, Wang XX, He JF, Kang M, Zhang RL, Zhang J, Wu JB, Hu SX, Zhang HJ, Liu XQ, Fu WJ, Ou JM, Wu SG, Qin Y, Zhang ZJ, Shi YJ, Zhang JJ, Artois J, Fang VJ, Zhu HC, Guan Y, Gilbert M, Horby PW, Leung GM, Gao GF, Cowling BJ, Yu HJ (2017) Epidemiology of avian influenza A H7N9 virus in human beings across five epidemics in mainland China, 2013-17: an epidemiological study of laboratoryconfirmed case series. Lancet Infect Dis 17(8):822-832. https ://doi.org/10.1016/S1473-3099(17)30323-7

4. Chen JD, Zhang JP, Zhu WJ, Zhang YS, Tan HL, Liu MF, Cai MS, Shen JR, Ly H, Chen JH (2017) First genome report and analysis of chicken $\mathrm{H} 7 \mathrm{~N} 9$ influenza viruses with poly-basic amino acids insertion in the hemagglutinin cleavage site. Sci Rep UK. https://doi.org/10.1038/S41598-017-10605-6

5. Zhou L, Tan Y, Kang M, Liu FQ, Ren RQ, Wang YL, Chen T, Yang YP, Li C, Wu J, Zhang HJ, Li D, Greene CM, Zhou SZ, Iuliano AD, Havers F, Ni DX, Wang DY, Feng ZJ, Uyeki TM, Li Q (2017) Preliminary epidemiology of human infections with highly pathogenic avian influenza $\mathrm{A}(\mathrm{H} 7 \mathrm{~N} 9)$ virus, China. Emerg Infect Dis 23(8):1355-1359. https://doi.org/10.3201/ eid2308.170640

6. Ke CW, Mok CKP, Zhu WF, Zhou HB, He JF, Guan WD, Wu J, Song WJ, Wang DY, Liu JX, Lin QH, Chu DKW, Yang L, Zhong NS, Yang ZF, Shu YL, Peiris JSM (2017) Human infection with highly pathogenic avian influenza A (H7N9) virus, China. Emerg Infect Dis 23(8):1332-1340. https://doi. org/10.3201/eid2308.170600

7. Kang M, Lau EHY, Guan W, Yang Y, Song T, Cowling BJ, Wu J, Peiris M, He J, Mok CKP (2017) Epidemiology of human infections with highly pathogenic avian influenza $\mathrm{A}(\mathrm{H} 7 \mathrm{~N} 9)$ virus in Guangdong, 2016 to 2017. Eurosurveillance 22(27):26. https://doi.org/10.2807/1560-7917.Es.2017.22.27.30568

8. Zhang FC, Bi YH, Wang J, Wong G, Shi WF, Hu FY, Yang Y, Yang LQ, Deng XL, Jiang SF, He X, Liu YX, Yin CB, Zhong NS, Gao GF (2017) Human infections with recently-emerging highly pathogenic H7N9 avian influenza virus in China. J Infect 75(1):71-74. https://doi.org/10.1016/j.jinf.2017.04.001

9. Gao GF (2014) Influenza and the Live Poultry Trade. Science 344(6181):235-235. https://doi.org/10.1126/science.1254664

10. Li J, Yu XF, Pu XY, Xie L, Sun YX, Xiao HX, Wang FJ, Din H, Wu Y, Liu D, Zhao GQ, Liu J, Pan JC (2013) Environmental connections of novel avian-origin H7N9 influenza virus infection and virus adaptation to the human. Sci China Life Sci 56(6):485-492. https://doi.org/10.1007/s11427-013-4491-3

11. Latham T, Galarza JM (2001) Formation of wild-type and chimeric influenza virus-like particles following simultaneous expression of only four structural proteins. J Virol 75(13):61546165. https://doi.org/10.1128/Jvi.75.13.6154-6165.2001 
12. Kemp TJ, Safaeian M, Hildesheim A, Pan YJ, Penrose KJ, Porras C, Schiller JT, Lowy DR, Herrero R, Pinto LA (2012) Kinetic and HPV infection effects on cross-type neutralizing antibody and avidity responses induced by Cervarix (R). Vaccine 31(1):165170. https://doi.org/10.1016/j.vaccine.2012.10.067

13. Cox MMJ (2012) Recombinant protein vaccines produced in insect cells. Vaccine 30(10):1759-1766. https://doi.org/10.1016/j. vaccine.2012.01.016

14. Mena JA, Kamen AA (2011) Insect cell technology is a versatile and robust vaccine manufacturing platform. Expert Rev Vaccines 10(7):1063-1081. https://doi.org/10.1586/Erv.11.24

15. Zhang QY, Shi JZ, Deng GH, Guo J, Zeng XY, He XJ, Kong HH, Gu CY, Li XY, Liu JX, Wang GJ, Chen Y, Liu LL, Liang LB, Li YY, Fan J, Wang JL, Li WH, Guan LZ, Li QM, Yang HL, Chen PC, Jiang L, Guan YT, Xin XG, Jiang YP, Tian GB, Wang XR, Qiao CL, Li CJ, Bu ZG, Chen HL (2013) H7N9 influenza viruses are transmissible in ferrets by respiratory droplet. Science 341(6144):410-414. https://doi.org/10.1126/science.1240532

16. Shi JZ, Deng GH, Kong HH, Gu CY, Ma SJ, Yin X, Zeng XY, Cui PF, Chen Y, Yang HL, Wan XP, Wang XR, Liu LL, Chen PC, Jiang YP, Liu JX, Guan YT, Suzuki Y, Li M, Qu ZY, Guan LZ, Zang JK, Gu WL, Han SU, Song YM, Hu YZ, Wang Z, Gu LL, Yang WY, Liang LB, Bao HM, Tian GB, Li YB, Qiao CL, Jiang L, Li CJ, Bu ZG, Chen HL (2017) H7N9 virulent mutants detected in chickens in China pose an increased threat to humans. Cell Res 27(12):1409-1421. https://doi.org/10.1038/cr.2017.129

17. Abe T, Takahashi H, Hamazaki H, Miyano-Kurosaki N, Matsuura Y, Takaku H (2003) Baculovirus induces an innate immune response and confers protection from lethal influenza virus infection in mice. J Immunol 171(3):1133-1139

18. Zhu W, Zhou J, Li Z, Yang L, Li X, Huang W, Zou S, Chen W, Wei H, Tang J, Liu L, Dong J, Wang D, Shu Y (2017) Biological characterisation of the emerged highly pathogenic avian influenza (HPAI) A (H7N9) viruses in humans, in mainland China, 2016 to 2017. Eurosurveillance 22(19):2-6. https://doi.org/10.2807/15607917.Es.2017.22.19.30533

19. Zhu WF, Dong J, Zhang Y, Yang L, Li XY, Chen T, Zhao X, Wei HJ, Bo H, Zeng XX, Huang WJ, Li Z, Tang J, Zhou JF, Gao RB,
Xin L, Yang J, Zou SM, Chen WB, Liu J, Shu YL, Wang DY (2018) A gene constellation in avian influenza A (H7N9) viruses may have facilitated the fifth wave outbreak in China. Cell Rep 23(3):909-917. https://doi.org/10.1016/j.celrep.2018.03.081

20. Hu ZL, Liu XW, Jiao XN, Liu XF (2017) Newcastle disease virus (NDV) recombinant expressing the hemagglutinin of H7N9 avian influenza virus protects chickens against NDV and highly pathogenic avian influenza A (H7N9) virus challenges. Vaccine 35(48):6585-6590. https://doi.org/10.1016/j.vaccine.2017.10.010

21. Hu Z, Jiao X, Liu X (2017) Antibody immunity induced by H7N9 avian influenza vaccines: evaluation criteria, affecting factors, and implications for rational vaccine design. Front Microbiol 8:1898. https://doi.org/10.3389/fmicb.2017.01898

22. Stadlbauer D, Rajabhathor A, Amanat F, Kaplan D, Masud A, Treanor JJ, Izikson R, Cox MM, Nachbagauer R, Krammer F (2017) Vaccination with a recombinant $\mathrm{H} 7$ hemagglutinin-based influenza virus vaccine induces broadly reactive antibodies in humans. mSphere 2(6):e00502-17. https://doi.org/10.1128/mSphe re.00502-17

23. Kamal RP, Blanchfield K, Belser JA, Music N, Tzeng WP, Holiday C, Burroughs A, Sun XJ, Maines TR, Levine MZ, York IA (2017) Inactivated $H 7$ influenza virus vaccines protect mice despite inducing only low levels of neutralizing antibodies. J Virol 91(20):e01202-17. https://doi.org/10.1128/JVI.01202-17

24. Tan GS, Leon PE, Albrecht RA, Margine I, Hirsh A, Bahl J, Krammer F (2016) Broadly-reactive neutralizing and non-neutralizing antibodies directed against the $\mathrm{H} 7$ influenza virus hemagglutinin reveal divergent mechanisms of protection. PLoS Pathog 12(4):e1005578. https://doi.org/10.1371/journal.ppat.1005578

Publisher's Note Springer Nature remains neutral with regard to jurisdictional claims in published maps and institutional affiliations. 